\title{
Triamcinolone Acetonide Transdermal System SUN-131
}

National Cancer Institute

\section{Source}

National Cancer Institute. Triamcinolone Acetonide Transdermal System SUN-131. NCI

Thesaurus. Code C153426.

A transdermal system (TDS) containing triamcinolone acetonide, a synthetic glucocorticoid with anti-inflammatory and immunomodulating properties. Upon application of the TDS to the eyelid, triamcinolone acetonide binds to intracellular glucocorticoid receptors, ultimately inducing the expression of glucocorticoid-responsive genes and lipocortins. Lipocortins inhibit phospholipase $A 2$, thereby blocking the release of arachidonic acid from membrane phospholipids and preventing the synthesis of prostaglandins and leukotrienes, both mediators of inflammation. In addition, proinflammatory cytokine production, including interleukin (IL)-1 and IL-6, and the activation of cytotoxic T-lymphocytes is also inhibited. Triamcinolone acetonide also decreases the number of circulating lymphocytes, induces cell differentiation, and stimulates apoptosis through increasing Ikappa-B expression and curtailing activation of nuclear factor (NF)kappa-B. 